\title{
Predicting the dry matter intake of grazing dairy cows using infrared reflectance spectroscopy analysis
}

\author{
B. Lahart, ${ }^{1,2}$ S. McParland, ${ }^{1}$ E. Kennedy, ${ }^{1}$ T. M. Boland, ${ }^{2}$ T. Condon, ${ }^{1}$ M. Williams, ${ }^{1}$ N. Galvin, ${ }^{1}$ B. McCarthy, ${ }^{1}$ \\ and F. Buckley ${ }^{1 *}$ \\ ${ }^{1}$ Teagasc, Animal and Grassland Research and Innovation Centre, Moorepark, Fermoy, Co. Cork, Ireland P61 C997 \\ ${ }^{2}$ School of Agriculture and Food Science, University College Dublin, Belfield, Dublin 4, Ireland D04 N2E5
}

\section{ABSTRACT}

The objective of this study was to compare midinfrared reflectance spectroscopy (MIRS) analysis of milk and near-infrared reflectance spectroscopy (NIRS) analysis of feces with regard to their ability to predict the dry matter intake (DMI) of lactating grazing dairy cows. A data set comprising 1,074 records of DMI from 457 cows was available for analysis. Linear regression and partial least squares regression were used to develop the equations using the following variables: (1) milk yield (MY), fat percentage, protein percentage, body weight (BW), stage of lactation (SOL), and parity (benchmark equation); (2) MIRS wavelengths; (3) MIRS wavelengths, MY, fat percentage, protein percentage, BW, SOL, and parity; (4) NIRS wavelengths; (5) NIRS wavelengths, MY, fat percentage, protein percentage, BW, SOL, and parity; (6) MIRS and NIRS wavelengths; and (7) MIRS wavelengths, NIRS wavelengths, MY, fat percentage, protein percentage, BW, SOL, and parity. The equations were validated both within herd using animals from similar experiments and across herds using animals from independent experiments. The accuracy of equations was greater for within-herd validation compared with across-herds validation. Across-herds validation was deemed the more suitable method to assess equations for robustness and real-world application. The benchmark equation was more accurate [coefficient of determination $\left(R^{2}\right)=0.60$; root mean squared error $(\mathrm{RMSE})=1.68$ $\mathrm{kg}$ ] than MIRS alone $\left(\mathrm{R}^{2}=0.30 ; \mathrm{RMSE}=2.23 \mathrm{~kg}\right)$ or NIRS alone $\left(\mathrm{R}^{2}=0.16 ; \mathrm{RMSE}=2.43 \mathrm{~kg}\right)$. The combination of the benchmark equation with MIRS $\left(\mathrm{R}^{2}\right.$ $=0.64 ; \mathrm{RMSE}=1.59 \mathrm{~kg}$ ) resulted in slightly superior fitting statistics compared with the benchmark equation alone. The combination of the benchmark equation with NIRS $\left(\mathrm{R}^{2}=0.58 ; \mathrm{RMSE}=1.71 \mathrm{~kg}\right)$ did not

Received January 24, 2019.

Accepted May 21, 2019.

*Corresponding author: Frank.Buckley@teagasc.ie result in a more accurate prediction equation than the benchmark equation. The combination of MIRS and NIRS wavelengths resulted in superior fitting statistics compared with either method alone $\left(\mathrm{R}^{2}=0.36\right.$; RMSE $=2.15 \mathrm{~kg}$ ). The combination of the benchmark equation and MIRS and NIRS wavelengths resulted in the most accurate equation $\left(\mathrm{R}^{2}=0.68 ; \mathrm{RMSE}=1.52 \mathrm{~kg}\right)$. A further analysis demonstrated that Holstein-Friesian cows could predict the DMI of Jersey $\times$ HolsteinFriesian crossbred cows using both MIRS and NIRS. Similarly, the Jersey $\times$ Holstein-Friesian animals could predict the DMI of Holstein-Friesian cows using both MIRS and NIRS. The equations developed in this study have the capacity to predict DMI of grazing dairy cows. From a practicality perspective, MIRS in combination with variables in the benchmark equation is the most suitable equation because MIRS is currently used on all milk-recorded milk samples from dairy cows.

Key words: dry matter intake, near-infrared reflectance spectroscopy, mid-infrared reflectance spectroscopy, grazing dairy cow

\section{INTRODUCTION}

Feed efficiency is an important component of dairy systems (Berry and Crowley, 2013; Connor, 2015). A major obstacle to the direct inclusion of feed efficiency in dairy breeding programs is routine access to individual animal feed intake data from commercial dairy farms (Berry et al., 2014; Connor, 2015). In grazing systems, the measurement of individual animal feed intake is an extremely difficult task (Coleman, 2005). The n-alkane technique (Mayes et al., 1986; Dillon and Stakelum, 1989) is commonly used to estimate dietary DMI in grazing dairy cows (Prendiville et al., 2009; Schori and Münger, 2014; Hurley et al., 2017). However, this method is expensive and labor intensive and thus is applicable only under research conditions. The energy sinks milk production and BW have been widely used to predict the DMI of dairy cows (Vazquez and Smith, 2000; NRC, 2001). The identification of alterna- 
tive variables that explain additional variation on DMI may prove worthwhile, particularly if they have the potential to be recorded routinely at the commercial farm level.

Infrared reflectance spectroscopy measures the interaction of electromagnetic radiation with matter, which gives information on the chemical makeup of a constituent (Williams, 2005). Mid-infrared reflectance spectroscopy (MIRS) and near-infrared reflectance spectroscopy (NIRS) are both routinely used in the agrifood industry (McParland and Berry, 2016). The techniques differ in the region of the electromagnetic spectrum measured: MIRS uses the fundamental bands of molecular vibrations, whereas NIRS measures the overtones and combinations of these fundamental bands (Williams, 1987). Mid-infrared reflectance spectroscopy analysis of milk can provide information on detailed fatty acids (Soyeurt et al., 2011) and proteins (McDermott et al., 2016), whereas NIRS analysis of feces can be used to predict OM digestibility (Decruyenaere et al., 2009).

The ability of MIRS analysis of milk to estimate the intake of dairy cows has recently been documented (McParland et al., 2011; Shetty et al., 2017). Similarly, NIRS analysis of feces has been reported as a potentially useful method of estimating intake (Boval et al., 2004; Johnson et al., 2017). To date, no study has compared MIRS analysis of milk and NIRS analysis of feces to predict the DMI of dairy cows. A direct comparison among these methods to predict DMI in combination with known animal energy sinks and status traits would determine their accuracy, robustness, and aptness for use on commercial dairy farms.

A further consideration is the incidence of Jersey genetics among pasture-based dairy herds (Department of Agriculture, Food and the Marine, 2017). Associated with increased Jersey genetics in pasture-based systems is a propensity for increased DMI per unit of BW and consequent increases in production efficiency (Prendiville et al., 2009; Coffey et al., 2017). Hence, the evaluation of any methods to estimate DMI should take this subject into consideration.

The primary objective of this study was to evaluate the ability of MIRS of milk compared with NIRS of feces to predict the DMI of grazing dairy cows. A secondary objective was to compare equations to predict the DMI of Holstein-Friesian ( $\mathbf{H F}$ ) animals using HF $\times$ Jersey cross-bred $(\mathbf{J E} \times \mathbf{H F})$ animals and vice versa.

\section{MATERIALS AND METHODS}

Data were available from 4 Teagasc, Animal and Grassland, Research and Innovation Centre research herds as part of separate grazing research experiments.
Each experiment assessed the effect of altering dietary allowance on cow performance. Experiments assessed the effect of offering (1) perennial ryegrass (Lolium perenne L.) and white clover (Trifolium repens L.; McCarthy et al., 2015), (2) pasture at differing stocking rates $(2.5,2.9$, and 3.3 cows/ha; Coffey et al., 2017), (3) differing pasture allowances (60, 80, 100, and $120 \%$ of intake capacity) in early lactation (Kennedy et al., 2015), and (4) differing herbage and concentrate allowances across 2 genetic lines of HF (O'Sullivan et al., 2019). Experiments 1 to 3 comprised both HF and $\mathrm{JE} \times \mathrm{HF}$ cows, whereas experiment 4 exclusively comprised HF cows. Each experimental herd was managed in a rotational grazing system similar to that described by Roche et al. (2017), with fresh pasture allocated every 12 to $48 \mathrm{~h}$.

Across experiments, individual animal DMI was estimated up to 4 times during lactation. Dry matter intake was estimated in early, mid, and late lactation in experiments 1,2 , and 4 and early to mid lactation in experiment 3 . The diet of the animals consisted primarily of perennial ryegrass or perennial ryegrass plus supplementary concentrate $(0.9-3.6 \mathrm{~kg}$ of $\mathrm{DM} /$ cow per day).

\section{Measurements}

The DMI of the animals in all experiments was estimated using the n-alkane technique (Mayes et al., 1986) as modified by Dillon and Stakelum (1989). Briefly, cows were dosed twice daily after milking for a 12 -d period using paper pellets containing $500 \mathrm{mg}$ of C32-alkane (n-dotriacontane) each. Feces were sampled on d 7 to 12 before morning and evening milking. These samples were subsequently bulked ( $12 \mathrm{~g} /$ sample) and placed in a $40^{\circ} \mathrm{C}$ oven before being milled using a $1-\mathrm{mm}$ sieve. Herbage representative of that grazed by the cows was sampled manually on d 6 to 11 of each DMI estimation period. The ratio of naturally occurring C33-alkane (tritriacontane) in the herbage to dosed C32-alkane was used to calculate DMI.

Near-infrared reflectance values of the bulked fecal samples from each DMI estimation period were gathered using a Foss-NIRSystem 6500 SYII scanning monochromator (Foss-NIRSystems, Silver Spring, MD). Rectangular quartz cells (4.6 cm wide and $5.7 \mathrm{~cm}$ long) were used to scan each fecal sample. The spectral absorbance value of each fecal sample was recorded as log reflectance values over the wavelength range of 1,100 to $2,496 \mathrm{~nm}$ giving 699 individual data points. All spectral data points were retained for analysis.

Throughout each DMI estimation period, BW was recorded once following morning milking using calibrated weighing scales. Individual cow milk yield (MY) was 
recorded daily throughout each DMI estimation period using electronic milk meters (Dairymaster, Causeway, Co. Kerry, Ireland). Milk was sampled from consecutive evening and morning milkings once weekly during each DMI estimation period. These samples were analyzed using a Foss Milkoscan FT6000 spectrometer (Foss Electric A/S, Hillerød, Denmark) to determine fat and protein content. The milk mid-infrared spectral data were subsequently stored for further analysis. The Foss MIR spectrum contains 1,060 data points representing the absorption of infrared light through the milk sample in the mid-infrared region of 900 to $5,000 \mathrm{~cm}^{-1}$. Spectral data were transformed from transmittance to linear absorbance through log transformation of the reciprocal wavelength values (Soyeurt et al., 2011). Wavelength regions associated with water absorption (Shetty et al., 2017) were omitted, resulting in the spectral data points between 925 to $1,600 \mathrm{~cm}^{-1}$ and 1,700 to 3,005 $\mathrm{cm}^{-1}$ being retained for analysis.

\section{Treatment of Spectral Data}

Boxcar smoothing (rolling averages) of both NIRS and MIRS was implemented by averaging the spectra over segments of 5 data points in length (Williams, 2005). The first derivative was calculated on both the smoothed and unsmoothed spectra to sharpen absorbance bands (Williams, 2005). The first derivative (f'x) was calculated as the difference between the spectral value at data point $\mathrm{x}$ and the spectral value at the data point $\mathrm{x}+5$.

\section{Data Editing}

The data set comprised 1,681 individual records of DMI, of which 1,379 were HF and 302 were $\mathrm{JE} \times \mathrm{HF}$. Records missing BW ( $\mathrm{n}=53)$, MIRS $(\mathrm{n}=452)$, or NIRS $(\mathrm{n}=167)$ spectra were removed. Values of DMI, BW, MY, fat percentage, and protein percentage were examined using PROC UNIVARIATE (SAS Institute Inc., Cary, NC), and 14 records were removed as they were deemed erroneous. Principal component analysis (PROC PRIN COMP) was used to generate the first 2 principal components for the MIRS and NIRS spectra. The Mahalanobis distance from the centroid of the MIRS and NIRS clusters was calculated. Samples with a Mahalanobis distance greater than the 99.9th percentile of the chi-squared distribution with 2 degrees of freedom were considered outliers. This revealed no NIRS outliers and 15 MIRS outliers, which were removed. Animals of third parity plus were grouped together. Stage of lactation (SOL) was defined as (1) $<49$, (2) 50 to 99, (3) 100 to 189, and (4) >190 DIM.
After all edits were completed there were 1,074 (815 $\mathrm{HF}$ and $259 \mathrm{JE} \times \mathrm{HF}$ ) records available for analysis from 457 (337 $\mathrm{HF}$ and $120 \mathrm{JE} \times \mathrm{HF}$ ) individual cows. The mean breed proportion of the HF animals was $73 \%$ Holstein and 26\% Friesian, whereas the mean breed proportion of the $\mathrm{JE} \times \mathrm{HF}$ animals was $40 \%$ Holstein, 11\% Friesian, and 47\% Jersey (Irish Cattle Breeding Federation national database).

\section{Prediction Equations}

Equations to predict DMI were developed using the following variables: (1) MY, fat percentage, protein percentage, BW, SOL, and parity, which was used as a benchmark with which the following could be compared; (2) MIRS wavelengths; (3) MIRS wavelengths, $\mathrm{MY}$, fat percentage, protein percentage, BW, SOL, and parity; (4) NIRS wavelengths; (5) NIRS wavelengths, MY, fat percentage, protein percentage, BW, SOL, and parity; (6) MIRS and NIRS wavelengths; and (7) MIRS wavelengths, NIRS wavelengths, MY, fat percentage, protein percentage, BW, SOL, and parity. Linear regression was used to develop equation 1 , whereas partial least squares (PLS) regression (PROC PLS) was used to develop all other equations. Splitsample cross-validation was initially undertaken on all PLS models and involved removing every 20th sample from the data set and predicting it using data from the remaining data set. This was repeated until every sample had been predicted once. The optimal number of PLS factors retained within the models was defined as the minimum number of factors needed to achieve the lowest root mean predicted residual sum of squares. All equations were subsequently validated within herd and across herds.

Within-herd validation involved stratifying the data set by experiment, DMI estimation period, and breed; $25 \%$ of the records were removed for validation, and the remaining $75 \%$ of the data were used to develop the models. No animal was present in the training and validation data sets at the same time. This procedure was repeated 4 times until all records had been tested using within-herd validation once. The association between predicted and observed DMI was assessed using regression analysis. The following metrics were used to assess the accuracy and robustness of the models: the coefficient of determination $\left(\mathbf{R}^{2}\right)$ between true and predicted DMI values, the root mean squared error (RMSE) from plotting predicted versus observed DMI, the slope between true and predicted DMI values, the mean bias of prediction, and the ratio of performance deviation (RPD; Williams, 2005; Derby, 2010). The $\mathrm{R}^{2}$, RMSE, RPD, and number of factors were reported 
as the average of the 4 iterations of within-herd validation. The mean bias and slope were reported as the range of values across the 4 iterations.

Across-herds validation was undertaken to assess whether equations could predict the DMI of an independent group of experimental animals. This was undertaken in 2 phases by using 3 out of the 4 experiments to develop the models; the remaining experiment was used for external validation. This was iterated until each experiment had been predicted once. The $\mathrm{R}^{2}$, RMSE, RPD, and number of factors were reported as the average of the 4 iterations of across-herds validation. The mean bias and slope were reported as the range of values across the 4 iterations.

To determine the ability of the individual breeds to perform predictions on one another, all records of $\mathrm{HF}$ animals were removed from the training data set and were used as a validation data set, whereas the $\mathrm{JE} \times \mathrm{HF}$ animals alone were used to train the model. The procedure was repeated by removing the $\mathrm{JE} \times$ $\mathrm{HF}$ animals from the training data set to be used as a validation data set, and the $\mathrm{HF}$ animals alone were used to train the model. Models 3 (MIRS wavelengths, MY, fat percentage, protein percentage, BW, SOL, and parity) and 5 (NIRS wavelengths, MY, fat percentage, protein percentage, BW, SOL, and parity) were used. Animals from experiment $4(\mathrm{n}=553)$ were removed from this part of the analysis because it contained only $\mathrm{HF}$ animals, resulting in 521 records $(\mathrm{HF}=262 ; \mathrm{JE} \times$ $\mathrm{HF}=259)$ being available for analysis.

\section{RESULTS}

Mean values ( \pm SD in parentheses) of DMI, MY, fat percentage, protein percentage, lactose percentage, BW, parity, and DIM across the data set were 15.7 $\mathrm{kg} / \mathrm{d}(3.1), 20.4 \mathrm{~kg} / \mathrm{d}(5.4), 4.5 \%(0.7), 3.7 \%(0.4)$, $4.8 \%(0.2), 499 \mathrm{~kg}(69), 2.0$ (0.8), and $124 \mathrm{~d}(64)$, respectively. A breakdown of these values for each of the
4 experiments represented in the data set is presented in Table 1.

Using smoothed MIRS and NIRS wavelengths did not improve the $\mathrm{R}^{2}$ of prediction over the $\mathrm{R}^{2}$ of the unsmoothed wavelengths. Likewise, the first derivative of the smoothed and unsmoothed MIRS and NIRS spectra did not result in more accurate predictions. The results presented therefore are from the untreated spectra.

\section{Within-Herd Validation}

Table 2 presents the fitting statistics for all 7 equations evaluated to predict DMI upon within-herd validation. The use of the animal traits MY, fat percentage, protein percentage, BW, SOL, and parity (benchmark equation) resulted in a mean $\mathrm{R}^{2}$ of 0.71 (range $=$ $0.69-0.73$ ) and an RMSE of $1.67 \mathrm{~kg}$ (range $=1.61-1.80$ $\mathrm{kg})$. Using MIRS wavelengths alone to predict DMI resulted in inferior fitting statistics compared with the benchmark equation, with a mean $\mathrm{R}^{2}$ of 0.48 (range $=$ $0.46-0.52$ ) and an RMSE of $2.24 \mathrm{~kg}$ (range $=2.07-2.37$ $\mathrm{kg}$ ). Combining MIRS wavelengths with the variables in the benchmark equation resulted in a mean $R^{2}$ of 0.76 (range $=0.75-0.77$ ) and an RMSE of $1.51 \mathrm{~kg}$ (range $=$ $1.44-1.60 \mathrm{~kg}$ ), which was higher than the benchmark equation. Using NIRS wavelengths alone resulted in a mean $\mathrm{R}^{2}$ of 0.50 (range $=0.48-0.52$ ) and a mean RMSE of $2.19 \mathrm{~kg}$ (range $=2.12-2.32 \mathrm{~kg}$ ). Similar to MIRS, the combination of NIRS wavelengths with the variables in the benchmark equation resulted in superior fitting statistics compared with the benchmark equation, with a mean $\mathrm{R}^{2}$ of 0.76 (range $=0.76-0.78$ ) and an RMSE of $1.50 \mathrm{~kg}$ (range $=1.40-1.58 \mathrm{~kg}$ ). Combining MIRS wavelengths and NIRS wavelengths resulted in superior fitting statistics compared with either method alone, with an $\mathrm{R}^{2}$ of 0.56 (range $=0.54-0.58$ ) and an RMSE of $2.06 \mathrm{~kg}(1.93-2.16 \mathrm{~kg})$. The combination of the variables in the benchmark equation with NIRS and MIRS resulted in the most accurate equation, with a mean $R^{2}$

Table 1. Mean ( \pm SD in parentheses) phenotypic values for each experiment

\begin{tabular}{|c|c|c|c|c|}
\hline \multirow[b]{2}{*}{ Item } & \multicolumn{4}{|c|}{ Experiment $^{1}$} \\
\hline & 1 & 2 & 3 & 4 \\
\hline No. of records/cows & $99 / 37$ & $281 / 131$ & $141 / 82$ & $553 / 207$ \\
\hline DMI (kg) & $17.1(2.3)$ & $15.7(3.0)$ & $12.8(2.4)$ & $16.2(3.0)$ \\
\hline Milk yield (kg) & $21.0(4.7)$ & $20.1(5.2)$ & $21.6(5.2)$ & $20.1(5.6)$ \\
\hline Fat $(\%)$ & $4.6(0.6)$ & $4.8(0.7)$ & $4.6(0.6)$ & $4.3(0.7)$ \\
\hline Protein (\%) & $3.9(0.3)$ & $3.7(0.4)$ & $3.2(0.3)$ & $3.7(0.3)$ \\
\hline Lactose (\%) & $4.8(0.2)$ & $4.8(0.2)$ & $4.8(0.1)$ & $4.8(0.2)$ \\
\hline BW (kg) & $495(59)$ & $482(72)$ & $456(62)$ & $518(62)$ \\
\hline Parity & $2.3(0.8)$ & $2.2(0.9)$ & $2.0(0.9)$ & $1.9(0.7)$ \\
\hline DIM & $117(55)$ & $122(68)$ & $60(24)$ & $142(60)$ \\
\hline
\end{tabular}

${ }^{1} 1$ = McCarthy et al. (2015); 2 = Coffey et al. (2017); 3 = Kennedy et al. (2015); 4 = O'Sullivan et al. (2019). 


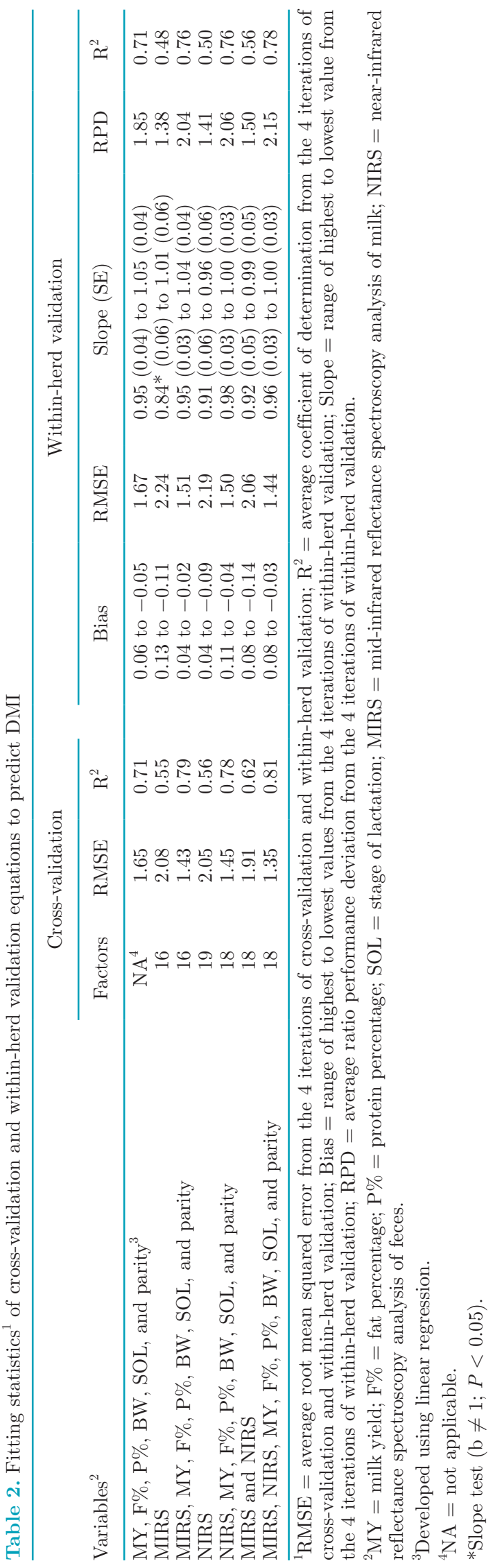

of 0.78 (range $=0.77-0.80$ ) and an RMSE of $1.44 \mathrm{~kg}$ $($ range $=1.33-1.51 \mathrm{~kg})$.

\section{Across-Herds Validation}

Table 3 presents the fitting statistics for all 7 equations to predict DMI upon across-herds validation. The benchmark equation resulted in a mean $\mathrm{R}^{2}$ of 0.60 (range $=0.51-0.68$ ) and an RMSE of $1.68 \mathrm{~kg}$ (range $=$ $1.33-2.08 \mathrm{~kg}$ ). The use of MIRS wavelengths alone to predict DMI resulted in inferior fitting statistics compared with the benchmark equation, with a mean $\mathrm{R}^{2}$ of 0.30 (range $=0.15-0.48$ ) and a mean RMSE of $2.23 \mathrm{~kg}$ (range $=1.70-2.68 \mathrm{~kg})$. Combining MIRS wavelengths with the variables in the benchmark equation resulted in slightly superior fitting statistics compared with the benchmark equation alone, with a mean $\mathrm{R}^{2}$ of 0.64 (range $=0.51-0.74$ ) and an RMSE of $1.59 \mathrm{~kg}$ (range $=1.20-1.77 \mathrm{~kg}$ ). The use of NIRS wavelengths alone to predict DMI resulted in a mean $\mathrm{R}^{2}$ of 0.16 (range $=$ 0.01-0.39) and an RMSE of $2.43 \mathrm{~kg}$ (range $=2.09-3.00$ $\mathrm{kg})$. The combination of NIRS wavelengths with the variables in the benchmark equation did not result in superior fitting statistics compared with the benchmark equation alone, with a mean $\mathrm{R}^{2}$ of 0.58 (range $=$ $0.48-0.64$ ) and an RMSE of $1.71 \mathrm{~kg}$ (range $=1.41-1.90$ $\mathrm{kg}$ ). When NIRS and MIRS were used together to predict DMI, the accuracy was greater compared with either method alone, with a mean $\mathrm{R}^{2}$ of 0.36 (range $=0.28-0.46$ ) and a mean RMSE of $2.15 \mathrm{~kg}$ (range $=$ $1.73-2.56 \mathrm{~kg}$ ). The combination of the variables in the benchmark equation with MIRS and NIRS resulted in the most accurate equation, with a mean $R^{2}$ of 0.68 (range $=0.62-0.75)$ and an RMSE of $1.52 \mathrm{~kg}$ (range $=$ $1.18-1.76 \mathrm{~kg})$.

\section{Individual Breed Equations}

Tables 4 and 5 present the fitting statistics of equations to predict the DMI of the individual breeds using equations 3 (MIRS wavelengths, MY, fat percentage, protein percentage, BW, SOL, and parity) and 5 (NIRS wavelengths, MY, fat percentage, protein percentage, BW, SOL, and parity), respectively. The DMI of HF animals could be predicted when $\mathrm{JE} \times \mathrm{HF}$ animals were used to develop equations, and vice versa when HF animals were used to develop the equations.

\section{DISCUSSION}

The major obstacle to genetic improvements in feed efficiency of dairy cows is routine access to individual animal feed intake data from commercial dairy farms (Berry et al., 2014; Connor, 2015). Thus, despite known 


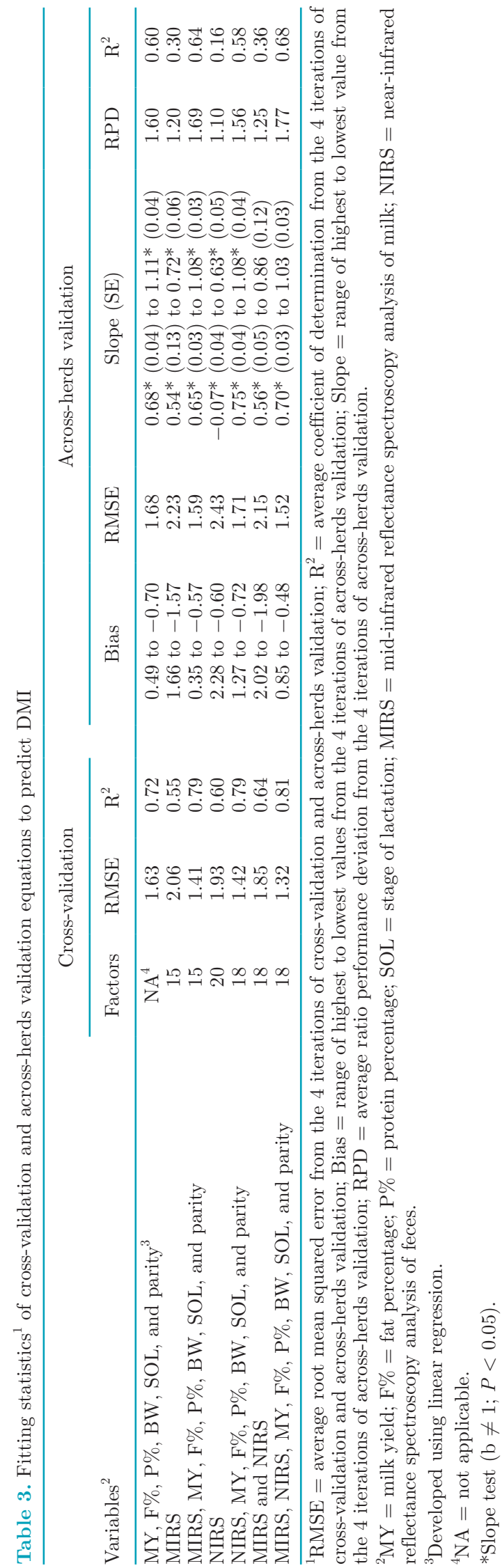

genetic variation for feed intake and efficiency in grazing dairy cows (Berry et al., 2007; Hurley et al., 2017), progress in including the trait in breeding indexes has been limited. There is an interest in the development of technologies to estimate the feed intake of a large population of dairy animals to derive breeding values for feed efficiency (Berry and Crowley, 2013). The analysis of feces and milk using infrared reflectance spectroscopy to predict DMI has been previously researched (Tran et al., 2010; Shetty et al., 2017; Dórea et al., 2018). Both approaches offer the potential to collect phenotypes relating to feed intake across a large population of animals. However, a direct comparison of the 2 methods, either as prediction methods in their own right or in combination with other variables, has not been conducted.

\section{Validation Methodology}

The majority of previous NIRS and MIRS studies developed equations to predict DMI by randomly selecting a proportion of either cows or samples from the total data set for training purposes and using remaining samples for validation (Boval et al., 2004; Shetty et al., 2017; Wallén et al., 2018). Although demonstrating the potential of the technologies, the results are not necessarily a true representation of the predictive accuracy of equations (Dórea et al., 2018). This study compared the effects of validating equations both within herd (with cows from within the same experiment) and across herds (using differing experiments), providing greater confidence about the true applicability of the equations.

\section{Evaluation of Equations to Predict DMI}

The fitting statistics of all equations were inferior upon across-herds validation compared with withinherd validation. This is not surprising because the prediction of DMI across differing environments is a very difficult task (Pulina et al., 2013). Similar intakes can be achieved from different underlying principles (McParland and Berry, 2016). The strong prediction of DMI by the benchmark equation is supported by previous studies using similar variables (Vazquez and Smith, 2000; NRC, 2001; McCarthy et al., 2014). The energy sinks milk production and BW are positively correlated with DMI on genetic (Manzanilla Pech et al., 2014) and phenotypic (Prendiville et al., 2009) levels. This strong relationship is linked to the cow's inherent desire to satisfy its energetic demands for milk production and maintenance requirements (Holmes et al., 2002). For the purpose of this study, the benchmark equation was 
Table 4. Fitting statistics ${ }^{1}$ of breed equations to predict DMI using mid-infrared reflectance spectroscopy analysis of milk, milk yield, fat percentage, protein percentage, BW, parity, and stage of lactation

\begin{tabular}{|c|c|c|c|c|c|c|c|c|c|c|}
\hline Calibration $^{2}$ & \multicolumn{3}{|c|}{ Cross-validation } & Validation & \multicolumn{6}{|c|}{ Validation } \\
\hline $\mathrm{HF}$ & 262 & 1.45 & 0.78 & $\mathrm{JE} \times \mathrm{HF}$ & 259 & 0.002 & 1.61 & $0.98(0.03)$ & 1.89 & 0.72 \\
\hline
\end{tabular}

${ }^{1} \mathrm{RMSE}=$ root mean squared error; $\mathrm{R}^{2}=$ coefficient of determination between true and predicted values; $\mathrm{RPD}=$ ratio performance deviation. ${ }^{2} \mathrm{HF}=$ Holstein Friesian; JE $\times \mathrm{HF}=$ Holstein Friesian $\times$ Jersey cross-breed.

*Slope test $(\mathrm{b} \neq 1 ; P<0.05)$.

used as a standard with which equations incorporating infrared spectroscopy could be compared.

Corresponding to the results of Dórea et al. (2018), who examined MIRS of milk from TMR-fed Holsteins, using MIRS alone to predict DMI led to inferior fitting statistics compared with the benchmark equation upon across-herds validation, although the fitting statistics themselves were superior to those of Dórea et al. (2018; $\left.\mathrm{R}^{2}=0.17\right)$. The differences observed may be due to the use of differing wavelength regions, differing methods of analysis, and the diet offered to the cows. The milk of grass-fed cows has a different profile for fatty acids compared with that of TMR-fed cows (White et al., 2001; O'Callaghan et al., 2016). Shetty et al. (2017) postulated that the fatty acid profile of milk from grazing dairy cows may result in more accurate predictions of DMI compared with that of milk from TMR-fed cows. Another study by McParland et al. (2012), using MIRS analysis of milk, reported an $\mathrm{R}^{2}$ of 0.08 for energy intake. The equations were developed on Holstein cows offered a TMR diet and validated on a separate herd of HF grazing dairy cows. In contrast, the herds used to validate equations in this study comprised cows of similar genetics offered broadly similar diets. McParland et al. (2012) hypothesized that the dissimilarity in the spectral profiles between the 2 production systems resulted in the poor validation. Similarly, a study by Johnson et al. (2017), using NIRS analysis of feces from feedlot-housed beef cattle, stated that the large dissimilarity in the spectral profiles of the differing experiments may have resulted in the poor accuracy $\left(\mathrm{R}^{2}<\right.$
0.05). In this study, the experimental research herds had quite similar spectral profiles for both MIRS (Figure 1) and NIRS (Figure 2), which may have contributed to more accurate predictions. Nevertheless, the fitting statistics of both the MIRS and NIRS equations when used individually to predict DMI were poor. Robust prediction models require sufficient quantities of spectral variation relevant to the environmental conditions upon which the equations are to be used (McParland and Berry, 2016; Johnson et al., 2017). This hypothesis is supported by the study of Tran et al. (2010), who developed a robust fecal NIRS equation $\left(\mathrm{R}^{2}=0.67\right)$ using commercial dairy farms from 27 locations across 2 countries. Similarly, in other fields in agriculture where infrared reflectance spectroscopy is routinely used, the more samples and the more diverse the profile of these samples, the greater the aptness of the developed equations for use on external data sets (Burns et al., 2010; Soyeurt et al., 2011).

The improvement in the fitting statistics when MIRS was combined with the variables in the benchmark equation agrees with previous studies using MIRS and animal traits (Shetty et al., 2017; Dórea et al., 2018; Wallén et al., 2018). Mid-infrared reflectance spectroscopy provided additional information relating to DMI moderately surpassing the benchmark equation. The majority of the observed predictability would appear to be due to its ability to predict fat and protein content in the milk. The inclusion of fat and protein content in the equation including MY, BW, SOL, and parity led to a 0.08 increase in the $\mathrm{R}^{2}$ (results not shown).

Table 5. Fitting statistics ${ }^{1}$ of breed equations to predict DMI using near-infrared reflectance spectroscopy analysis of feces, milk yield, fat percentage, protein percentage, BW, parity, and stage of lactation

\begin{tabular}{|c|c|c|c|c|c|c|c|c|c|c|}
\hline Calibration $^{2}$ & \multicolumn{3}{|c|}{ Cross-validation } & Validation & \multicolumn{6}{|c|}{ Validation } \\
\hline $\mathrm{JE} \times \mathrm{HF}$ & 259 & 1.38 & 0.79 & $\mathrm{HF}$ & 262 & -0.17 & 1.69 & $0.91 *(0.04)$ & 1.87 & 0.71 \\
\hline
\end{tabular}

${ }^{1} \mathrm{RMSE}=$ root mean squared error; $\mathrm{R}^{2}=$ coefficient of determination between true and predicted values; $\mathrm{RPD}=$ ratio performance deviation. ${ }^{2} \mathrm{HF}=$ Holstein Friesian; JE $\times \mathrm{HF}=$ Holstein Friesian $\times$ Jersey cross-breed.

*Slope test $(\mathrm{b} \neq 1 ; P<0.05)$. 


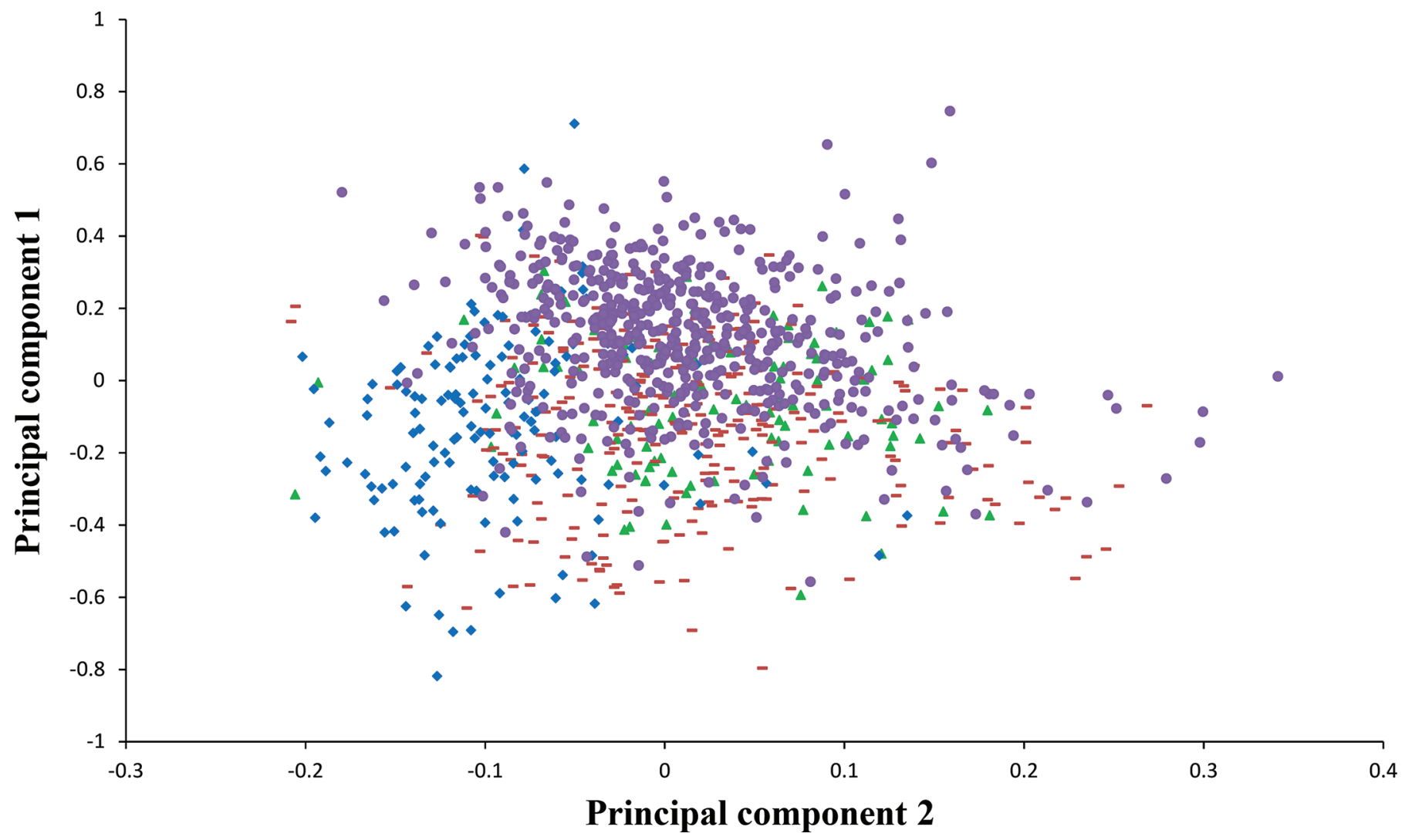

Figure 1. First 2 principal components of spectral data of milk showing experiments 1 (green triangles), 2 (red dashes), 3 (blue diamonds), and 4 (purple circles). Principal component 1 explained $79 \%$ of spectral variation, and principal component 2 explained $9 \%$ of spectral variation.

There was an additional 0.04 increase in the $R^{2}$ when MIRS was combined with the aforementioned variables. Removing fat and protein content from this equation (equation 3) did not affect prediction accuracy (results not shown). Mid-infrared reflectance spectroscopy analysis can provide information on detailed fatty acids (Soyeurt et al., 2011) and proteins (McDermott et al., 2016), opposed to the nonspecific versions of fat and protein used in the benchmark equation. This may be a reason for the additional variation on DMI explained by MIRS within the current study. Shetty et al. (2017) reported no advantage for DMI prediction of including MIRS compared with including milk fat and protein content in a prediction model based on cows offered a TMR diet. However, Dórea et al. (2018) found significant improvements in DMI prediction when artificial neural networks were implemented on the spectra of milk from TMR-fed cows, suggesting a possible nonlinear relationship between DMI and the milk spectra.

There was no advantage for DMI prediction when NIRS was combined with the variables in the benchmark equation. Previous authors have noted that NIRS analysis of feces can provide information on the digestibility of the diet as well as the physiological state of the animal (Decruyenaere et al., 2009; Dixon and Coates, 2009). However, when known animal energy sinks and status traits are accounted for, additional contribution to DMI prediction would appear nonevident. It should be highlighted that the combination of both NIRS and MIRS with the benchmark equation led to the most accurate equation, indicating that both methods of analysis complement one another when predicting DMI. Specific fecal NIRS wavelength regions associated with the by-products of feed digestion may become relevant predictors of DMI only when the corresponding milk MIRS wavelength regions produced from the digestion of this feed are present.

Similar to the results of McParland et al. (2014), the RPD for all the equations fitted in the current study were lower than the recommended threshold of 2.4 for the purpose of rough screening proposed by Williams (2005). This recommendation is for predicting parameters that have a precise gold standard measure as a reference value. Hence, the use of this guideline on equations to predict DMI, which is regulated by complex natural processes (Holmes et al., 2002; Coleman, 2005; Pulina et al., 2013), is debatable (Johnson et al., 2017). More so, because DMI in grazing animals 
is estimated using the n-alkane technique and not measured directly, a prediction accuracy of near unity is not expected (McParland and Berry, 2016).

\section{Prediction of the Individual Breeds}

Despite having slightly differing spectral profiles (Figure 3), HF animals could be used successfully to predict the DMI of JE $\times$ HF animals using MIRS in combination with the variables in the benchmark equation and vice versa with $\mathrm{JE} \times \mathrm{HF}$ animals. Shetty et al. (2017) was also able to predict the DMI of pure Jersey cows with the milk spectra of Holstein animals in combination with MY and BW, although the fitting statistics reported were lesser compared with the current study. The mean breed proportion of the $\mathrm{JE} \times \mathrm{HF}$ animals within the current study was $47 \%$ Jersey and $51 \% \mathrm{HF}$, which may have led to an increase in the accuracy upon validation. Holstein-Friesian animals could also be used successfully to predict the DMI of JE $\times$ HF animals using NIRS in combination with the variables in the benchmark equation, and vice versa with $\mathrm{JE} \times \mathrm{HF}$ animals. The spectral profiles of the feces of both genotypes were similar (Figure 4). Furthermore,
Beecher et al. (2014) noted that there was no difference in the digestibility and rumen microbial populations between the breeds. The same study also showed that $\mathrm{JE} \times \mathrm{HF}$ animals are lighter and have a significantly different gastrointestinal tract weight compared with HF animals, resulting in differences in total DMI and DMI per unit of BW reported by Prendiville et al. (2009) and Coffey et al. (2017). However, there were only minor discrepancies in the bias of predictions.

\section{Application of Equations}

A further consideration is the commercial application of the equations. Methods of predicting DMI for the purposes of improving feed efficiency must be easily deployed on commercial dairy farms. The majority of the variables in the benchmark equation are readily available, with the possible exception of BW. Nevertheless, many commercial dairy farms have access to weighing scales for the purpose of weighing growing replacement animals. Because MIRS is currently used to measure the milk constituents of milk-recorded animals (McParland et al., 2014; Shetty et al., 2017), it is ideally suited to collect phenotypes of DMI. However,

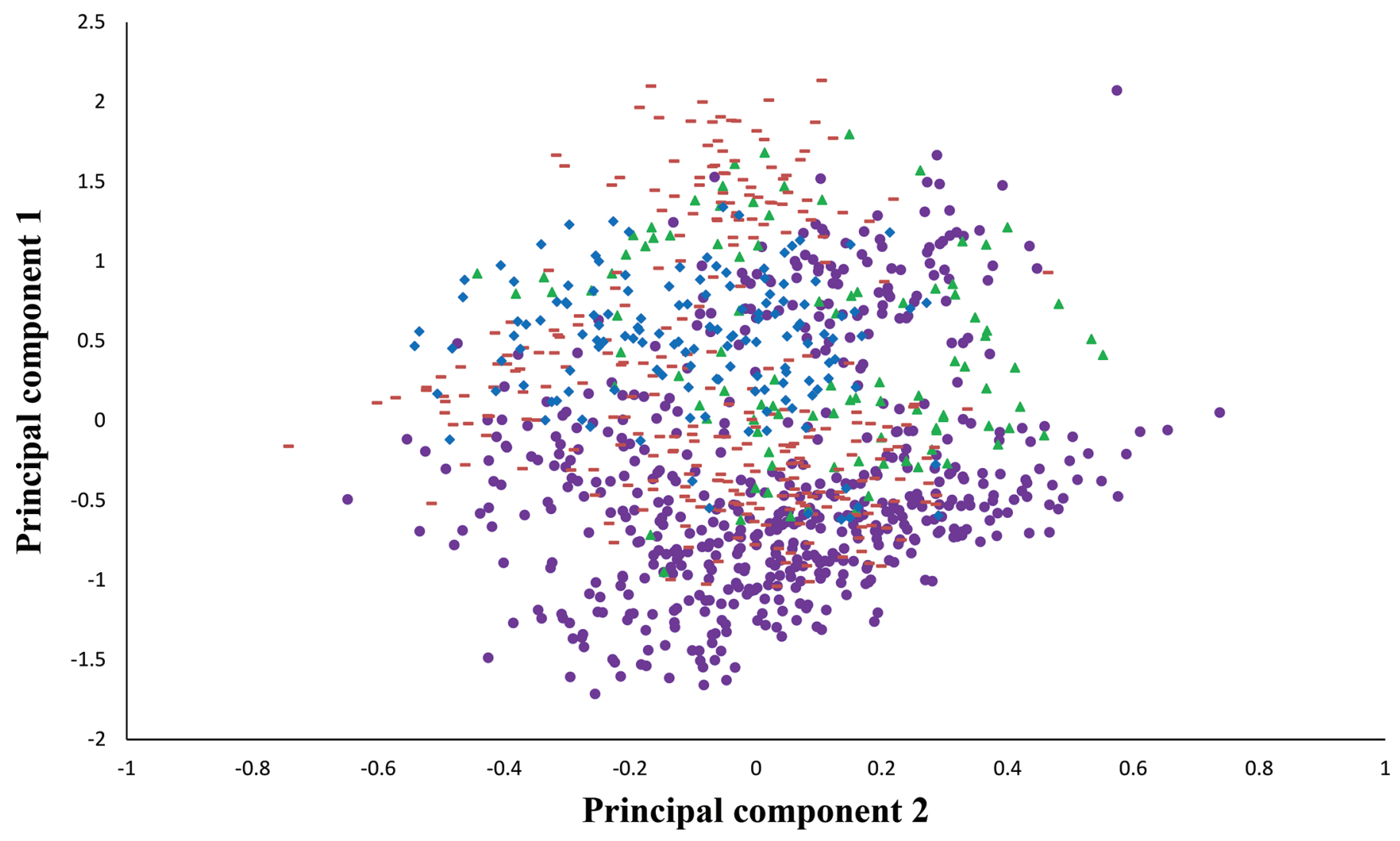

Figure 2. First 2 principal components of spectral data of feces showing experiments 1 (green triangles), 2 (red dashes), 3 (blue diamonds), and 4 (purple circles). Principal component 1 explained $92 \%$ of spectral variation, and principal component 2 explained $7 \%$ of spectral variation. 


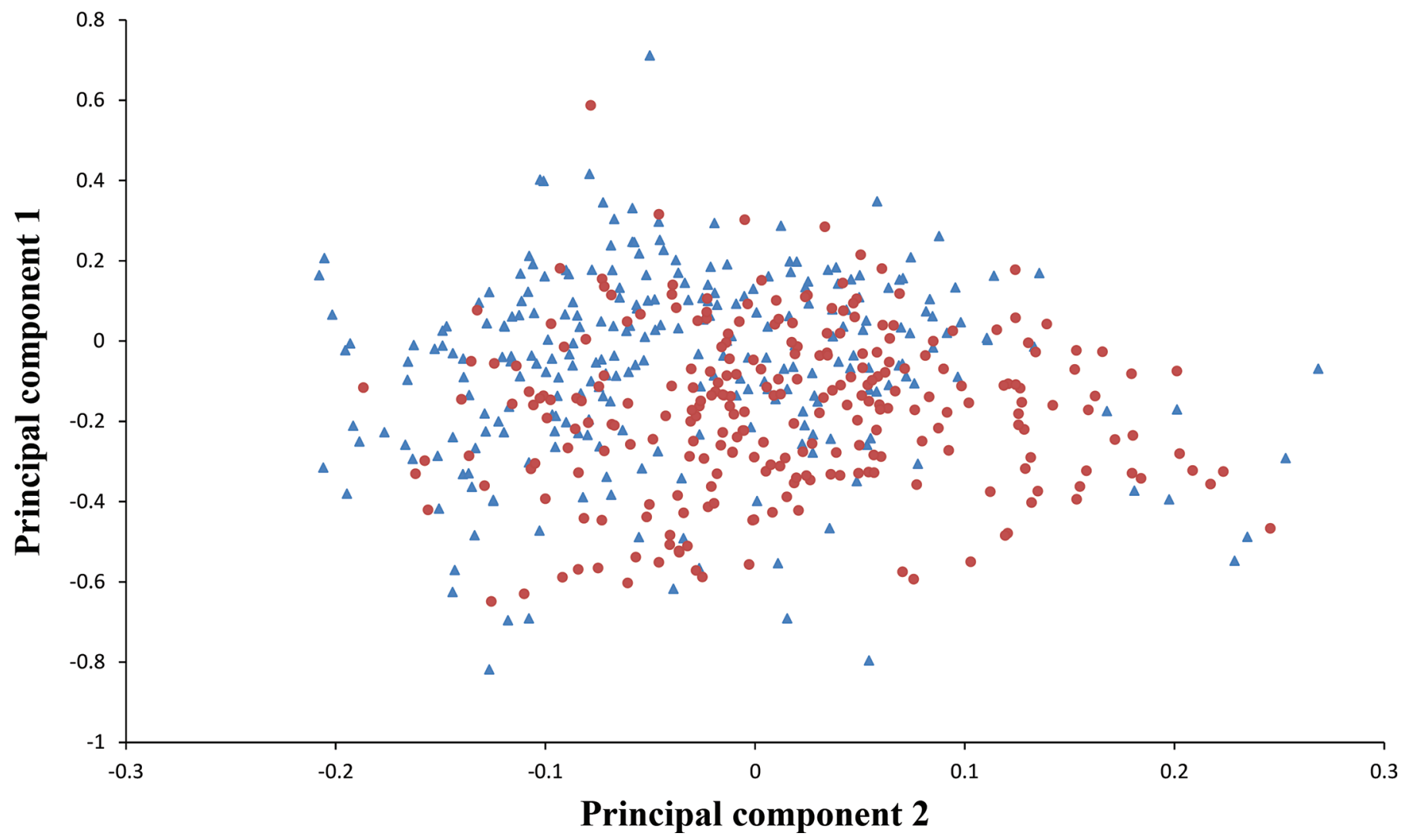

Figure 3. First 2 principal components of spectral data of milk showing Holstein-Friesian (blue triangles) and Holstein-Friesian $\times$ Jersey crossbred (red circles) cows. Principal component 1 explained $76 \%$ of spectral variation, and principal component 2 explained $12 \%$ of spectral variation.

NIRS analysis used within this study is labor intensive because the fecal samples used were a composite of several subsamples that were subsequently bulked, dried, and milled before analysis, suggesting that the combination of the MIRS wavelengths with the variables in the benchmark equation is the most suitable equation for predicting the DMI of grazing dairy cows.

It is acknowledged that the developed equations do not capture all of the variation in DMI. Variables such as pregrazing herbage mass and herbage allowance also influence DMI in grazing dairy cows (Kennedy et al., 2008; Muñoz et al., 2016). Further improvements to the predictive accuracy of DMI equations may be realized where accurate data on such variables are used in prediction models (O'Neill et al., 2013a,b). However, these data are not readily available on commercial dairy farms. Additionally, highly accurate phenotypes in absolute terms are not necessarily required to make genetic progress for a trait once sufficient quantities of phenotypic records are available (Calus et al., 2013; McParland and Berry, 2016). Given that half of the Irish dairy cow population is milk recorded annually (Roche et al., 2017), equations developed in this study offer potential to collect phenotypes of DMI from a large population of animals for use in breeding for genetic improvements in feed efficiency.

\section{CONCLUSIONS}

The equations developed in this study have the capacity to predict DMI of lactating dairy cows under grazing conditions. The use of MIRS analysis of milk in combination with known animal energy sinks and status traits is proposed as the most suitable method for the collection of phenotypic feed intake data. In addition, the DMI of HF animals could be predicted when $\mathrm{JE} \times \mathrm{HF}$ animals were used to develop equations and vice versa when HF animals were used to develop the equations.

\section{ACKNOWLEDGMENTS}

The authors gratefully acknowledge funding by the Irish Government under the National Development Plan 2007-2013 through the Department of Agriculture, Food and the Marine (Dublin, Ireland) Research 


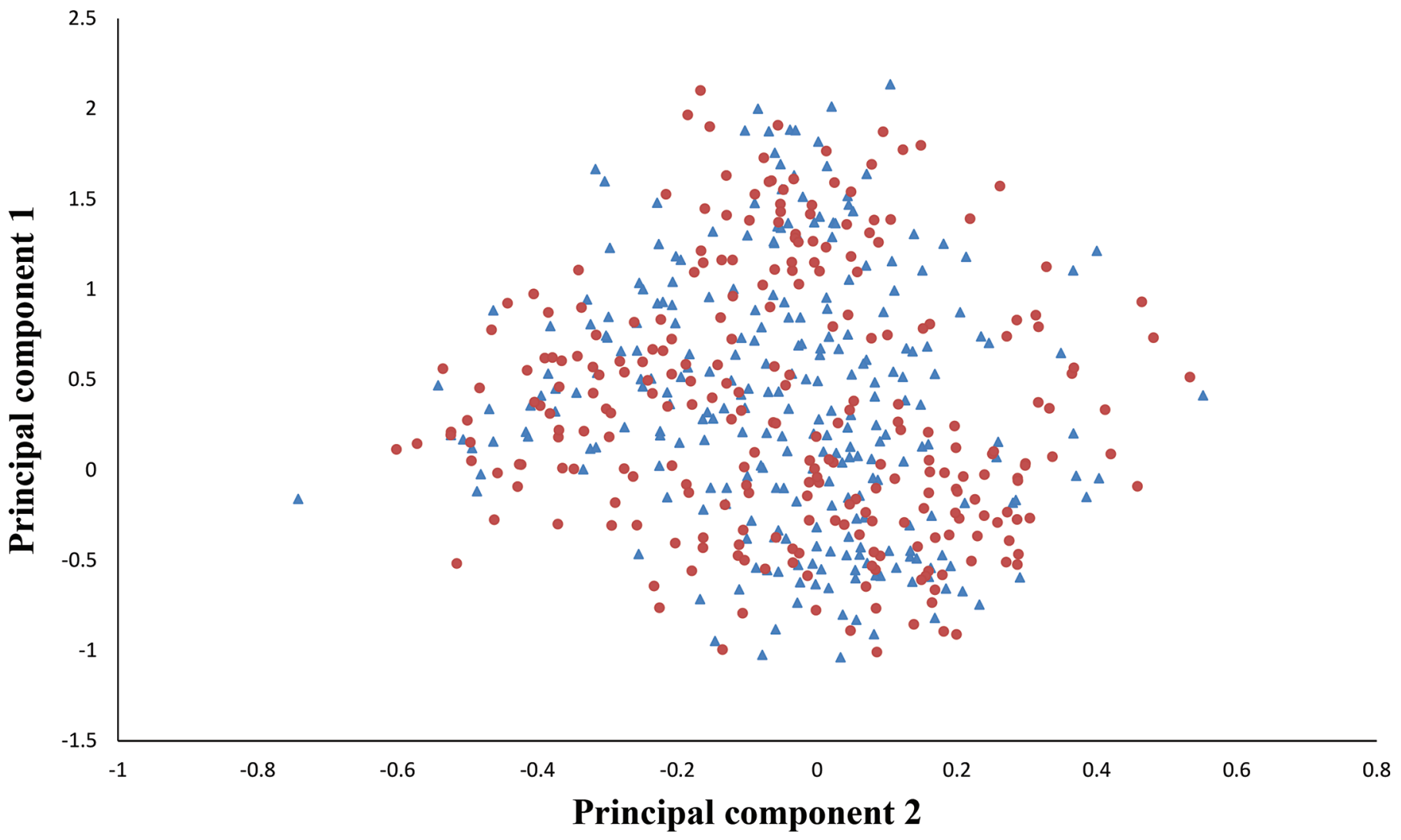

Figure 4. First 2 principal components of spectral data of feces showing Holstein-Friesian (blue triangles) and Holstein-Friesian $\times$ Jersey crossbred (red circles) cows. Principal component 1 explained $90 \%$ of spectral variation, and principal component 2 explained $9 \%$ of spectral variation.

Stimulus Fund 13/S/496 RAPIDFEED. The diligent work of the farm staff and students on the 4 research farms in collecting the data used in the current study is also acknowledged.

\section{REFERENCES}

Beecher, M., F. Buckley, S. M. Waters, T. M. Boland, D. EnriquezHidalgo, M. H. Deighton, M. O'Donovan, and E. Lewis. 2014. Gastrointestinal tract size, total-tract digestibility, and rumen microflora in different dairy cow genotypes. J. Dairy Sci. 97:3906-3917.

Berry, D. P., B. Horan, M. O’Donovan, F. Buckley, E. Kennedy, M. McEvoy, and P. Dillon. 2007. Genetics of grass dry matter intake, energy balance, and digestibility in grazing Irish dairy cows. J. Dairy Sci. 90:4835-4845.

Berry, D. P., M. P. Coffey, J. E. Pryce, Y. de Haas, P. Løvendahl, N. Krattenmacher, J. J. Crowley, Z. Wang, D. Spurlock, K. Weigel, K. Macdonald, and R. F. Veerkamp. 2014. International genetic evaluations for feed intake in dairy cattle through the collation of data from multiple sources. J. Dairy Sci. 97:3894-3905.

Berry, D. P., and J. J. Crowley. 2013. Genetics of feed efficiency in dairy and beef cattle. J. Anim. Sci. 91:1594-1613.

Boval, M., D. B. Coates, P. Lecomte, V. Decruyenaere, and H. Archimède. 2004. Faecal near infrared reflectance spectroscopy (NIRS) to assess chemical composition, in vivo digestibility and intake of tropical grass by Creole cattle. Anim. Feed Sci. Technol. 114:19-29.
Burns, G., T. Gilliland, D. McGilloway, M. O'Donovan, E. Lewis, N. Blount, and P. O'Kiely. 2010. Using NIRS to predict composition characteristics of Lolium perenne L. cultivars. Adv. Anim. Biosci. $1: 321$.

Calus, M. P., Y. De Haas, M. Pszczola, and R. Veerkamp. 2013. Predicted accuracy of and response to genomic selection for new traits in dairy cattle. Animal 7:183-191.

Coffey, E. L., L. Delaby, S. Fitzgerald, N. Galvin, K. M. Pierce, and B. Horan. 2017. Effect of stocking rate and animal genotype on dry matter intake, milk production, body weight, and body condition score in spring-calving, grass-fed dairy cows. J. Dairy Sci. 100:7556-7568.

Coleman, S. W. 2005. Predicting forage intake by grazing ruminants. Pages 72-90 in Proc. 2005 Ruminant Nutrition Symposium, Florida. University of Florida Dairy Extension.

Connor, E. E. 2015. Invited review: Improving feed efficiency in dairy production: Challenges and possibilities. Animal 9:395-408.

Decruyenaere, V., P. Lecomte, C. Demarquilly, J. Aufrere, P. Dardenne, D. Stilmant, and A. Buldgen. 2009. Evaluation of green forage intake and digestibility in ruminants using near infrared reflectance spectroscopy (NIRS): Developing a global calibration. Anim. Feed Sci. Technol. 148:138-156.

Department of Agriculture, Food and the Marine. 2017. AIM Bovine Statistics Report 2017. Department of Agriculture, Food and the Marine, Dublin, Ireland.

Derby, N. Getting correct results from PROC REG. Paper 270 in Proc. SAS Global Forum 2010, Seattle, WA. SAS Institute Inc., Cary, NC. 
Dillon, P., and G. Stakelum. 1989. Herbage and dosed alkanes as a grass management technique for dairy cows. Irish. J. Agric. Res. 28:104. (Abstr.)

Dixon, R., and D. Coates. 2009. Review: Near infrared spectroscopy of faeces to evaluate the nutrition and physiology of herbivores. J Near Infr. Spectr. 17:1-31.

Dórea, J. R., G. Rosa, K. Weld, and L. Armentano. 2018. Mining data from milk infrared spectroscopy to improve feed intake predictions in lactating dairy cows. J. Dairy Sci. 101:5878-5889.

Holmes, C., I. Brookes, D. Garrick, D. Mackenzie, T. Parkinson, and G. Wilson. 2002. Milk Production from Pasture: Principles and Practices. Massey University, Palmerston North, New Zealand.

Hurley, A. M., N. López-Villalobos, S. McParland, E. Lewis, E. Kennedy, M. O’Donovan, J. L. Burke, and D. P. Berry. 2017. Genetics of alternative definitions of feed efficiency in grazing lactating dairy cows. J. Dairy Sci. 100:5501-5514.

Johnson, J. R., G. E. Carstens, S. D. Prince, K. H. Ominski, K. M. Wittenberg, M. Undi, T. D. A. Forbes, A. N. Hafla, D. R. Tolleson, and J. A. Basarab. 2017. Application of fecal near-infrared reflectance spectroscopy profiling for the prediction of diet nutritional characteristics and voluntary intake in beef cattle. J. Anim. Sci. 95:447-454.

Kennedy, E., L. Delaby, B. Horan, J. Roche, and E. Lewis. 2015. Duration is important in the effect of pasture allowance restriction on subsequent milk production, in early lactation. Pages 110-112 in Grassland Science in Europe, Vol. 20-Grassland and Forages in High Output Dairy Farming Systems. European Grassland Federation, Wageningen, the Netherlands.

Kennedy, E., M. O'Donovan, L. Delaby, and F. P. O'Mara. 2008. Effect of herbage allowance and concentrate supplementation on dry matter intake, milk production and energy balance of early lactating dairy cows. Livest. Sci. 117:275-286.

Manzanilla Pech, C. I., R. Veerkamp, M. Calus, R. Zom, A. van Knegsel, J. Pryce, and Y. De Haas. 2014. Genetic parameters across lactation for feed intake, fat-and protein-corrected milk, and liveweight in first-parity Holstein cattle. J. Dairy Sci. 97:5851-5862.

Mayes, R., C. Lamb, and P. M. Colgrove. 1986. The use of dosed and herbage n-alkanes as markers for the determination of herbage intake. J. Agric. Sci. 107:161-170.

McCarthy, B., M. Dineen, C. Guy, F. Coughlan, and T. Gilliland. The effect of tetraploid and diploid perennial ryegrass swards sown with and without clover on milk and herbage production. Pages 259-261 in Grassland Science in Europe, Vol. 20-Grassland and Forages in High Output Dairy Farming Systems. European Grassland Federation, Wageningen, the Netherlands.

McCarthy, J., B. McCarthy, B. Horan, K. Pierce, N. Galvin, A. Brennan, and L. Delaby. 2014. Effect of stocking rate and calving date on dry matter intake, milk production, body weight, and body condition score in spring-calving, grass-fed dairy cows. J. Dairy Sci. 97:1693-1706.

McDermott, A., G. Visentin, M. De Marchi, D. Berry, M. Fenelon, P. O'Connor, O. Kenny, and S. McParland. 2016. Prediction of individual milk proteins including free amino acids in bovine milk using mid-infrared spectroscopy and their correlations with milk processing characteristics. J. Dairy Sci. 99:3171-3182.

McParland, S., G. Banos, B. McCarthy, E. Lewis, M. Coffey, B. O'Neill, M. O'Donovan, E. Wall, and D. Berry. 2012. Validation of mid-infrared spectrometry in milk for predicting body energy status in Holstein-Friesian cows. J. Dairy Sci. 95:7225-7235.

McParland, S., G. Banos, E. Wall, M. P. Coffey, H. Soyeurt, R. F. Veerkamp, and D. P. Berry. 2011. The use of mid-infrared spectrometry to predict body energy status of Holstein cows. J. Dairy Sci. 94:3651-3661.

McParland, S., and D. P. Berry. 2016. The potential of Fourier transform infrared spectroscopy of milk samples to predict energy intake and efficiency in dairy cows. J. Dairy Sci. 99:4056-4070.

McParland, S., E. Lewis, E. Kennedy, S. G. Moore, B. McCarthy, M. O'Donovan, S. T. Butler, J. E. Pryce, and D. P. Berry. 2014 Mid-infrared spectrometry of milk as a predictor of energy intake and efficiency in lactating dairy cows. J. Dairy Sci. 97:5863-5871.
Muñoz, C., P. A. Letelier, E. M. Ungerfeld, J. M. Morales, S. Hube, and L. A. Pérez-Prieto. 2016. Effects of pregrazing herbage mass in late spring on enteric methane emissions, dry matter intake, and milk production of dairy cows. J. Dairy Sci. 99:7945-7955.

NRC. 2001. Nutrient Requirements of Dairy Cattle. 7th rev. ed. Nat. Acad. Press, Washington, DC.

O'Callaghan, T. F., D. Hennessy, S. McAuliffe, K. N. Kilcawley, M. O'Donovan, P. Dillon, R. P. Ross, and C. Stanton. 2016. Effect of pasture versus indoor feeding systems on raw milk composition and quality over an entire lactation. J. Dairy Sci. 99:9424-9440.

O'Neill, B., E. Lewis, M. O'Donovan, L. Shalloo, N. Galvin, F. Mulligan, T. Boland, and R. Delagarde. 2013a. Predicting grass dry matter intake, milk yield and milk fat and protein yield of spring calving grazing dairy cows during the grazing season. Animal $7: 1379-1389$.

O'Neill, B. F., E. Lewis, M. O'Donovan, L. Shalloo, F. J. Mulligan, T. M. Boland, and R. Delagarde. 2013b. Evaluation of the GrazeIn model of grass dry-matter intake and milk production prediction for dairy cows in temperate grass-based production systems. 2Animal characteristics. Grass Forage Sci. 68:524-536.

O'Sullivan, M., B. Horan, K. M. Pierce, S. McParland, K. O'Sullivan, and F. Buckley. 2019. Milk production of Holstein-Friesian cows of divergent Economic Breeding Index evaluated under seasonal pasture-based management. J. Dairy Sci. 102:2560-2577.

Prendiville, R., K. M. Pierce, and F. Buckley. 2009. An evaluation of production efficiencies among lactating Holstein-Friesian, Jersey, and Jersey $\times$ Holstein-Friesian cows at pasture. J. Dairy Sci. 92:6176-6185.

Pulina, G., M. Avondo, G. Molle, A. H. D. Francesconi, A. S. Atzori, and A. Cannas. 2013. Invited review: Models for estimating feed intake in small ruminants. Rev. Bras. Zootec. 42:675-690.

Roche, J. R.. D. Berry, A. Bryant, C. Burke, S. Butler, P. Dillon, D. Donaghy, B. Horan, K. Macdonald, and K. Macmillan. 2017. A 100-year review: A century of change in temperate grazing dairy systems. J. Dairy Sci. 100:10189-10233.

Schori, F., and A. Münger. 2014. Intake, feed conversion efficiency and grazing behaviour of two Holstein cow strains in a pasture-based production system under organic farming in Switzerland. Org. Agric. $4: 175-186$.

Shetty, N., P. Løvendahl, M. S. Lund, and A. J. Buitenhuis. 2017. Prediction and validation of residual feed intake and dry matter intake in Danish lactating dairy cows using mid-infrared spectroscopy of milk. J. Dairy Sci. 100:253-264.

Soyeurt, H., F. Dehareng, N. Gengler, S. McParland, E. Wall, D. P. Berry, M. Coffey, and P. Dardenne. 2011. Mid-infrared prediction of bovine milk fatty acids across multiple breeds, production systems, and countries. J. Dairy Sci. 94:1657-1667.

Tran, H., P. Salgado, E. Tillard, P. Dardenne, X. T. Nguyen, and P. Lecomte. 2010. "Global" and "local" predictions of dairy diet nutritional quality using near infrared reflectance spectroscopy. J. Dairy Sci. 93:4961-4975.

Vazquez, O. P., and T. Smith. 2000. Factors affecting pasture intake and total dry matter intake in grazing dairy cows. J. Dairy Sci. 83:2301-2309.

Wallén, S. E., E. Prestløkken, T. Meuwissen, S. McParland, and D. Berry. 2018. Milk mid-infrared spectral data as a tool to predict feed intake in lactating Norwegian Red dairy cows. J. Dairy Sci. 101:6232-6243.

White, S. L., J. A. Bertrand, M. R. Wade, S. P. Washburn, J. T. Green Jr., and T. C. Jenkins. 2001. Comparison of fatty acid content of milk from Jersey and Holstein cows consuming pasture or a total mixed ration. J. Dairy Sci. 84:2295-2301.

Williams, P. 1987. Qualitative Applications of Near Infrared Reflectance Spectroscopy. American Association of Cereal Chemists, Eagan, MN.

Williams, P. 2005. Near-Infrared Technology_-Getting the Best Out of Light. PDK Projects Inc., Nanaimo, BC, Canada 